\title{
Common variants in the regulative regions of GRIA1 and GRIA3 receptor genes are associated with migraine susceptibility
}

\author{
Daniela Formicola1', Andrea Aloia', Simone Sampaolo², Olimpia Farina², Daria Diodato², Lyn R Griffiths33, \\ Fernando Gianfrancesco ${ }^{1}$, Giuseppe Di lorio² and Teresa Esposito*1
}

\begin{abstract}
Background: Glutamate is the principal excitatory neurotransmitter in the central nervous system which acts by the activation of either ionotropic (AMPA, NMDA and kainate receptors) or G-protein coupled metabotropic receptors. Glutamate is widely accepted to play a major role in the path physiology of migraine as implicated by data from animal and human studies. Genes involved in synthesis, metabolism and regulation of both glutamate and its receptors could be, therefore, considered as potential candidates for causing/predisposing to migraine when mutated.

Methods: The association of polymorphic variants of GRIA1-GRIA4 genes which encode for the four subunits (GluR1GluR4) of the alpha-amino-3- hydroxy-5-methyl-4-isoxazole-propionic acid (AMPA) receptor for glutamate was tested in migraineurs with and without aura (MA and $\mathrm{MO}$ ) and healthy controls.

Results: Two variants in the regulative regions of GRIA1 (rs2195450) and GRIA3 (rs3761555) genes resulted strongly associated with MA ( $P=0.00002$ and $P=0.0001$, respectively), but not associated with $M O$, suggesting their role in cortical spreading depression. Whereas the rs548294 variant in GRIA1 gene showed association primarily with $\mathrm{MO}$ phenotype, supporting the hypothesis that MA and MO phenotypes could be genetically related. These variants modify binding sites for transcription factors altering the expression of GRIA1 and GRIA3 genes in different conditions.
\end{abstract}

Conclusions: This study represents the first genetic evidence of a link between glutamate receptors and migraine.

\section{Background}

Migraine is a multifactorial disorder in which genetic factors play a relevant role in both predisposing and determining underlying mechanisms. Approaches to identified genes for monogenic subtypes migraine (e.g. Familial Hemiplegic Migraine - FHM) has been successful (CACNA1A, ATP1A2, SCN1A genes causing FMH 1, 2 and 3 respectively) [1-4]. Conversely, finding genes for the most frequent types of migraine (with and without aura) and defining their pathogenic role has proven much more difficult [5]. However, synaptic hyper-excitability has been invocated as one major pathogenic mechanism in both common and monogenic forms of migraine, and data from animal (experimental cortical spreading

\footnotetext{
* Correspondence: teresa.esposito@igb.cnr.it

${ }^{1}$ Institute of Genetics and Biophysics, Italian National Research Council, Naples, Italy

Full list of author information is available at the end of the article
}

depression; c-fos protein expression at the trigeminal nucleus caudalis, plasma protein extravasations at level of dura-mater circulation, electrophysiological studies) [6,7] and human (assessment of glutamate concentration in plasma, platelets and cerebrospinal fluid in migraneurs vs. control, glutamate and migraine symptoms; glutamate and sensitization) [8] studies suggest that glutamate is one of the principal factors involved.

Glutamate is the major excitatory neurotransmitter in the central nervous system which exerts this action mainly through its interaction with its ionotropic or metabotropic receptors.

In this study we investigated the association of GRIA1, GRIA2, GRIA3 and GRIA4 genes that encode for the four subunits (GluR1-GluR4) of the alpha-amino-3-hydroxy5-methyl-4-isoxazole-propionic acid (AMPA) ionotropic receptor and their variants to migraine with and without aura (MA and MO). 
This is the first study that shows a significant association between genetic variants of glutamate receptor and MA.

\section{Methods \\ Population Collection \& Phenotype}

Two hundred fifty outpatients consecutively observed from January 2006 to December 2008 at the Service of Diagnosis and Therapy of Headache of the Second University, Naples and two hundred sixty healthy volunteers consecutively enrolled during the same time interval were included in the study. Cases and controls were matched for sex, came from the same small geographical area and were Caucasian. All gave informed consent to the research procedures including molecular genetic analyses. The study protocol included history, direct clinical and neurological examination, MRI with both arterial and venous angiography sequences; venous blood collection for routine blood analysis as well as DNA extraction from lymphocytes according to standard salting out procedure [9]. Migraineurs were diagnosed as having either migraine with (MA) or migraine without (MO) aura, according to the 2004 International Headache Society [10] diagnostic criteria. The study population was comprised of 244 migraineurs (M/F 56/188; age 14-64 years; MA/MO 135/109); 7 patients who resulted affected with Familial Hemiplegic Migraine were excluded from the study.

For the statistical analysis three experimental groups were considered: all migraineurs together $(\mathrm{MA}+\mathrm{MO}=\mathrm{M})$ and MA and MO separately. Healthy control individuals (204 females and 56 males aged 21-64 years) of Caucasian origin matching for age and sex the migraineurs served as control for all three experimental groups.

\section{Polymorphisms selection and Genotyping}

SNP selection was performed inspecting the HapMap database PhaseIII/Rel 2, Feb09 on NCBI B36 assembly, dbSNP b126 http://www.hapmap.org/index.html.en. Default parameters in Haploview were used to create haplotype blocks (95\% confidence intervals) as described by Gabriel et al (2002) [11].

TagSNPs were selected at an $r^{2}$ threshold of 0.80 from all SNPs with minor allele frequency (MAF) $>0.15$ allowing us to capture more than $80 \%$ of the haplotypic diversity of these genes.

\section{GRIA1}

The gene maps on chromosome 5q33.2 and spans a genomic region of about $320 \mathrm{~kb}$. After consulting the HapMap database http://www.hapmap.org/index.html. en, we identified along the $320 \mathrm{~kb}$ of the GRIA1 gene four main blocks of linkage disequilibrium (LD) with few major haplotypes. The first block included the first two GRIA1 exons and the 5 upstream region. The second block was in intron 2, the third block included the exons 3-5, and the remaining part of the GRIA1 gene and the end was in the fourth block of LD. In consideration of the extension of LD inside each block we selected two SNPs in the first block, two SNPs in the fourth block and one SNP in the second and third blocks. In particular, the SNPs chosen were: rs548294, rs2195450, rs1463747, rs2963954, rs4530817 and rs1461225 (figure 1). All SNPs were genotyped by restriction digestion using the enzymes Mwol, TaqI, BsgI, RsaI, MnlI, and HpaI respectively.

\section{GRIA2}

For the GRIA2 gene, that expands a genomic region of $143 \mathrm{~kb}$ on chromosome 4q32.1, two main blocks of LD were identified. We selected four SNPs (two for each block): rs13138842, rs11946396, rs28495775 and rs11728471 that were genotyped by restriction digestion using the enzymes MluI, AccII, HuncII, and HphI respectively (figure 1).

\section{GRIA3}

The GRIA3 gene spans a genomic region of about $300 \mathrm{~kb}$ consisting of 17 exons, and is located in Xq24-q28 region, a critical region for migraine [12]. In a previous unpublished study we completely sequenced the coding and regulative regions of the GRIA3 gene in ten Italian migraine patients. We detected only a synonymous sequence variation in coding region $\mathrm{C} / \mathrm{T} \mathrm{N} 400 \mathrm{~N}$ (rs502434), and a number of SNPs located in intronic and promoter region. Taking in account SNPs distribution and LD-plot for GRIA3 gene, in a first step we selected 8 SNPs located in different LD-blocks: -1952T/C SNP (rs3761555) in the promoter region, the G/A SNP rs12559450 in intron 2, the G/A SNP rs4825840 in intron 2 , the C/A SNP rs4825849 in intron 3, the T/C SNP rs5911598 in intron 5, the C/T SNP N400N (rs502434) in exon 9, the C/T SNP rs2354037 in intron 12 and the T/C SNP rs5910006 in intron 14 (figure 1). In a preliminary analysis, using a smaller size cohort of migraine patients and controls (100 cases vs 100 controls) only one SNPs rs3761555 showed a trend of allelic differences between cases and controls, than was analysed in more detail. Genotyping was performed by restriction digestion using the enzyme BglII.

\section{GRIA4}

Also for the GRIA4 gene, which spans over $370 \mathrm{~kb}$ on chromosome 11q22.3, only two main blocks of LD were identified. We selected four SNPs (two for each block): rs11226805, rs590928, rs649098 and rs589104 that were genotyped by restriction digestion using the enzymes DdeI, Eco57I, MboI, and NlaIII respectively (figure 1).

All PCRs were performed as described in our previous work [13].

Briefly, PCR reactions (10 $\mu$ l final volume) containing 2 $\mathrm{mmol} / \mathrm{L} \mathrm{MgCl} 2,0.5 \mathrm{~mol} / \mathrm{L}$ of each primer, $200 \mathrm{~mol} / \mathrm{L}$ 


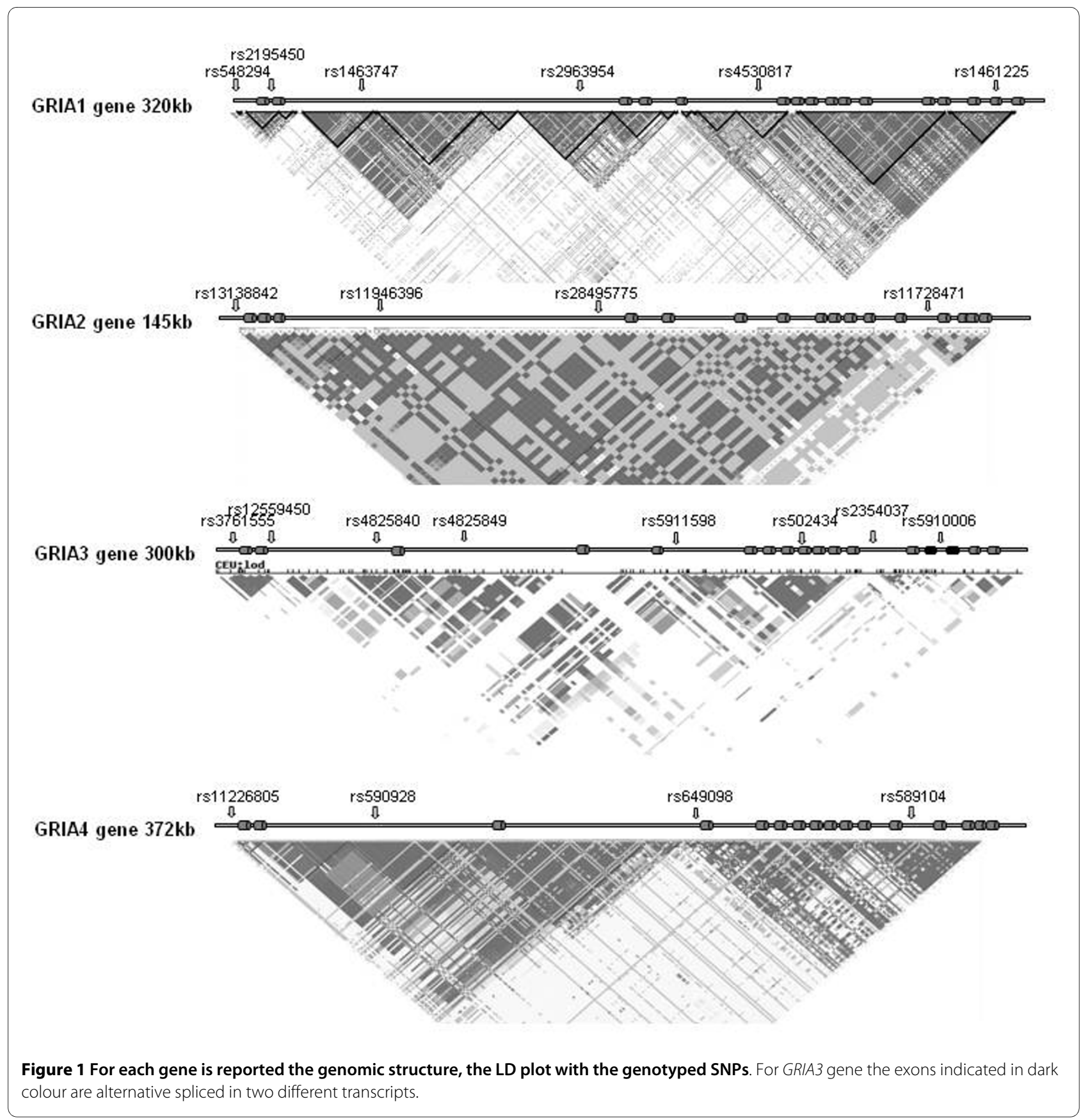

dNTPs, 1 unit of Taq polymerase (Fermentas) and approximately $20 \mathrm{ng}$ of genomic DNA were undertaken for genotyping purposes.

Thermal cycling was performed with an initial denaturation of 180 seconds at $94^{\circ} \mathrm{C}$, followed by 35 cycles of 30 $\mathrm{sec}$ at $94^{\circ} \mathrm{C}, 30 \mathrm{sec}$ at melting temperature (MT), $30 \mathrm{sec}$ at $72^{\circ} \mathrm{C}$, and a terminal extension of $10 \mathrm{~min}$ at $72^{\circ} \mathrm{C}$. PCR products were then digested with restriction enzymes and analyzed by electrophoresis on 3\% agarose gels. Ethidium bromide stained gels were digitally imaged and manually scored for genotypes. Table 1 shows the oligo sets and genotyping procedures for the GRIA1 and GRIA3 associated SNPs.

\section{Association Analysis}

To detect association between the tested markers and migraine, we performed chi-square $\left(x^{2}\right)$ analysis to test for significant differences in allele and genotype frequencies in case versus control results. $X^{2}$ provides the likelihood of a deviation in the distribution of the same attributes in different classes (e.g. allelic frequencies in controls versus affected subjects). If the probability ( $p-$ 
Table 1: primer sets, melting temperature (MT), PCRs size and genotyping conditions are reported for associated SNPs in GRIA1 and GRIA3 genes.

\begin{tabular}{llllllll}
\hline GENE & SNP & PRIMERS & MT & SIZE & ENZYME & ALLELE 1 (size) & ALLELE 2 (size) \\
\hline GRIA1 & rs548294 & $\begin{array}{l}\text { AGATGAAGAAACAGAGGTC } \\
\text { CCCCAGGTACTATTCAAAG }\end{array}$ & $56^{\circ} \mathrm{C}$ & $311 \mathrm{bp}$ & Mwol & $\mathrm{C}(123 / 188)$ & $\mathrm{T}(311)$ \\
GRIA1 & rs2195450 & $\begin{array}{l}\text { TCTAAGAGGAGGGGGAAGG } \\
\text { GCTTGGTAGATGGTGCTTGA }\end{array}$ & $60^{\circ} \mathrm{C}$ & $367 \mathrm{bp}$ & Taql & $\mathrm{G}(218 / 149)$ & $\mathrm{A}(367)$ \\
GRIA3 & rs3761555 & $\begin{array}{l}\text { CTGGAACAATGGAACAAAT } \\
\text { ATAATGCTATGTCCCTGTCT }\end{array}$ & $55^{\circ} \mathrm{C}$ & $272 \mathrm{bp}$ & Bglll & $\mathrm{T}(272)$ & $\mathrm{C}(111 / 161)$ \\
\hline
\end{tabular}

value) of an equal distribution between the two groups is below a determined significance level $\alpha$ (in percent), the statistical output will show enough significance to assume LD and therefore association. The $\mathrm{p}$ value of this test is asymptotically equal to the $\mathrm{p}$ value obtained in Armitage's trend test (ATT). ATT takes into account genotypes rather than alleles, avoiding a possible bias caused by doubling the sample size. It assumes an additive (or codominant) disease model where all disease alleles have equal and independent contribution to disease risk. The ATT is valid and powerful under a broad range of disease mechanisms. Second, allele and genotype frequencies, dominant and recessive genetic models as well as odds ratios were calculated to characterise the distribution of a distinct genotypes in different phenotypic subgroups of the population (using FINETTI, http://ihg.gsf.de/cgi-bin/ hw/hwa1.pl). Hardy-Weinberg Equilibrium (HWE) was also calculated using FINETTI. The analysis of the statistical power was performed using the Genetic Power Calculator software http://pngu.mgh.harvard.edu/ purcell/ gpc/cc2.html[14] assuming a significance level $(\alpha)$ of 0.05 , a lifetime risk of 2, and the MAF of each SNP as calculated in our control group. In the population-based association analysis, the nominal significance threshold was set at $\mathrm{P}<0.05$ and lowered to $\mathrm{P}<0.0017$ after the multiple comparison correction of Bonferroni considering 22 SNPs, the three clinical groups analyzed, genotypesalleles and females-males. Confidence intervals at 95\% are provided for all odds-ratio (OR) values. Haplotype frequencies were calculated using the Estimation Haplotype (EH) program (Jurg Ott, Rockefeller University). A P level of less than 0.05 was considered statistically significant.

\section{Electrophoretic mobility shift assays}

To determine whether the c. $-1952 \mathrm{~T}>\mathrm{C}$ SNP in GRIA3 promoter region alters nuclear protein-DNA interactions, EMSAs was performed using radio-labelled oligonucleotide probes containing either $-1952 \mathrm{~T}$ or $-1952 \mathrm{C}$. Nuclear extracts were prepared from HEK 293 and
SH5Y5Y cell lines as described by Granelli-Piperno et al. [15]. Binding reactions mixture contained $10 \mathrm{ng} 32 \mathrm{P}-$ labeled oligonucleotide probe $\left(10^{5} \mathrm{cpm}\right), 15 \mu \mathrm{g}$ nuclear extract, $2 \mu \mathrm{g}$ poly (dI-dC), $100 \mathrm{mM} \mathrm{KCl}, 10 \mathrm{mM} \mathrm{MgCl}$, 20 mM HEPES (pH 7.9), $0.2 \mathrm{mM}$ EDTA, $0.5 \mathrm{mM}$ dithiothreitol, $20 \%$ glycerol and protease inhibitor, in a total vol of $20 \mu \mathrm{l}$. To perform super shift experiments, $2 \mu \mathrm{g}$ of the anti-HSF1 antibody (Celbio) was added to the binding reaction mixture. In competition experiments, 100-fold molar excess of cold oligonucleotides was added to the binding reaction mixture. Reaction mixtures were incubated for $30 \mathrm{~min}$ at room temperature, resolved on nondenaturing $5 \%$ polyacrylamide gel, dried, and exposed to autoradiography. The same assay was performed for the c. $-2012 \mathrm{C}>\mathrm{T}$ SNP rs548294 in GRIA1 promoter region and for c. $+561 G>A$ SNP rs2195450 in intron 1.

Primers used for GRIA3 SNP were:

GRIA3-T-EMSA-F ATGGAGACAAAAGATTTCTATGAGTGGTGGGTGGG

GRIA3-T-EMSA-R TCCTCCCACCCACCACTCATA-

GAAATCTTTTGTCT

GRIA3-C-EMSA-F ATGGAGACAAAAGATCTCTAT

GAGTCGTGGGTGGG

GRIA3-C-EMSA-R TCCTCCCACCCACGACTCATA

GAG ATCTTTTGTCT

Primers used for GRIA1 SNP rs548294 were: GRIA1PROMF-T CAGTGCTTGCTGTTATTAGAGC CT

GRIA1PROMR-T TCTTAGGCTCTAATAACAGCAAGC

GRIA1PROMF-C CAGTGCTTGCTGCTATTAGA GCCT

GRIA1PROMR-C TCTTAGGCTCTAATAGCAGCA AGC

Primers used for GRIA1 SNP rs2195450 were:

GRIA1intF-G AAAGAGACCCTCGAGAAGAAGGAG

GRIA1intR-G CTCACTCCTTCTTCTCGAGGGTCT

GRIA1intF-A AAAGAGACCCTCAAGAAGAAGGAG

GRIA1intR-A CTCACTCCTTCTTCTTGAGGGTCT 


\section{Luciferase assays}

To test the functional activity of the $\mathrm{T}>\mathrm{C}$ polymorphism in the promoter region of the GRIA3 gene, we first identified the putative start site at -823 to the ATG, using the Promoter scan software vs2. A fragment of $1854 \mathrm{bp}$ of the GRIA3 promoter encompassing base pairs -1411 to +325 (referred to the predicted start site) and including the $\mathrm{T}>\mathrm{C}$ polymorphism was amplified from genomic DNA of migraine patients with genotype $\mathrm{CC}$ and controls with genotype TT. The primers used for generating this fragment were sense: 5'-GCGCGCCTCGAGTTTGAAGATGAGAGAACTGG-3' and antisense: 5'-GCGCGCAA GCTTCAAAAGAAAGAGAACGAAAG-3' which contain 5 '-XhoI and 3'-HindIII restriction sites (highlighted bold sequences), respectively.

PCR products were double digested using XhoI and HindIII and then legated into a linearized pGL3-Basic vector (Promega, Madison USA) containing a Firefly Luciferase reporter gene. The inserts of the constructs were verified by sequencing before transient transfection.

Transfections were carried out using HEK293T cells. Cells were co-transfected with $1 \mu \mathrm{g}$ of reporter plasmid and $10 \mathrm{ng}$ of pRL-TK control vector (Promega, Madison USA) containing Renilla luciferase, which was used to correct for transfection efficiency. Transfection cells were harvested after $24 \mathrm{~h}$ and cell lysates were assayed sequentially for Firefly and Renilla luciferase activity using a dual-reporter assay system (Promega, Madison USA). Transfections were performed in quadruplicate for each plasmid construct. Changes in gene transcription were calculated relative to the corrected luciferase activity of the empty pGL3-Basic vector (control).

\section{Ethical approval}

This research was reviewed and approved by the University of Naples Human Research Ethics Committee and all subjects participating in the study gave informed consent.

\section{Results}

\section{GRIA1 and GRIA3 genes are associated with migraine}

We selected SNPs for each gene (GRIA1-GRIA4) considering their distribution in LD blocks (figure 1). All variants were genotyped in a well-characterized panel of 244 cases and 260 controls (see methods). In controls, all SNPs analyzed are in Hardy-Weinberg equilibrium (HWE) (with the exception of rs2195450) and showed allele frequencies comparable to those observed in the Caucasian population and reported in the HapMap or SNP browser databases.

No significant association with the disease for any of the four SNPs in GRIA2 and GRIA4 genes tested was observed.

Significant association was observed for two SNPs located in the first block of LD of GRIA1 gene including the regulative region and the first two exons. Allelic and genotype frequencies distribution of the promoter 2012C/T (rs548294) marker in cases and controls showed significant association with migraine $(\mathrm{p}=0.00009$ and $\mathrm{p}=$ 0.0005 , respectively). Stratified analyses of migraine subtypes were also undertaken indicating association primarily attributed to $\mathrm{MO}$ subtype group $(\mathrm{P}=0.0003)$ and particularly in females $(\mathrm{P}=0.0007)$ (Table 2$)$. These differences remained statistically significant when Bonferroni correction for multiple comparisons was applied (Migraine all: alleles $\mathrm{p}=0.002$; genotypes $\mathrm{p}=0.01 ; \mathrm{MO}$ alleles: $\mathrm{p}=0.008$; genotypes $\mathrm{p}=0.03$; Females all: alleles $\mathrm{p}$ $=0.02$; genotypes $\mathrm{p}=0.05)$ (Table 2 ).

The analysis of the $+561 \mathrm{G}>\mathrm{A}$ SNP (rs2195450) also showed significant association in both allelic and genotype distributions $(\mathrm{p}=0.0002$ and $\mathrm{p}=0.0007$, respectively) $(\mathrm{p}=0.005$ and $\mathrm{p}=0.02$ after Bonferroni corrections). Stratified analyses of migraine subtypes showed a specific association with MA subtype group for both allelic and genotypic frequencies $(\mathrm{p}=0.00002$ and $\mathrm{p}$ $=0.00008)(\mathrm{p}=0.0005$ and $\mathrm{p}=0.002$ after Bonferroni corrections) (Table 2). However, the SNP rs2195450, was the only SNP found in Hardy-Weinberg disequilibrium (DHW) both in controls and in patients $(\mathrm{p}<0.05)$.

Regarding GRIA3 gene, we obtained statistically significant evidence for an association to migraine phenotype for the $-1952 \mathrm{~T} / \mathrm{C}$ variant (rs3761555) located in the regulative region of the gene (allele $\mathrm{C}$ frequencies: controlsmigraineurs $=22 \%$ vs. $34 \%$ ) (Table 2 ). In consideration of the $\mathrm{X}$ chromosomal localization of GRIA3 gene, we analyzed the data by gender, showing significant associations in females for both allelic and genotype distributions ( $\mathrm{p}=$ 0.0006 and $p=0.0009$, respectively). Stratified analyses of migraine subtypes showed a specific association with the female MA subtype group for either allelic or genotypic frequencies ( $\mathrm{p}=0.0001$ and $\mathrm{p}=0.0002$, respectively) (Table 2). These differences remained statistically significant after Bonferroni correction (alleles $\mathrm{p}=0.003$; genotypes $\mathrm{p}=0.005$ ) (Table 2$)$. The male group was not analyzed independently due to its limited size $(\mathrm{n}=56)$. The statistical power for the three associated SNPs in GRIA1 and GRIA3 genes was $97 \%$ for rs548294, 97\% for rs2195450 and 93\% for rs3761555. When we calculated the statistical power for subgroups (MA, MO, females, males) it remained high in MA and females, but it decreased for MO and males subgroup due to their limited size. We analyzed the distribution of the haplotypes formed by the associated SNPs in GRIA1 gene in cases and controls. Haplotype frequencies (calculated using the $\mathrm{EH}$ program) were significantly different in cases and controls (chi-square $=12.72, \mathrm{df}=3$, p-value 0.005). Haplotype-specific testing showed that the putative risk haplotype T_A (rs548294-rs2195450) was more frequent in cases than in controls, resulting in p-value of 0.002 and an 
Table 2: Allele and genotype frequencies of GRIA1 and GRIA3 polymorphisms in Italian patients and controls and association results

\begin{tabular}{|c|c|c|c|c|c|c|c|c|c|c|c|c|c|}
\hline Gene & SNP & SAMPLE & $\mathbf{N}$ & MAF & SP & MAJOR HOMO & HET & $\begin{array}{l}\text { MINOR } \\
\text { HOMO }\end{array}$ & $\begin{array}{l}\text { ALLELE } \\
\text { P-VALUE }\end{array}$ & 11 vs 12 & $\begin{array}{l}\text { GENOTYPE } \\
\text { P-VALUE } \\
11 \text { vs } 22\end{array}$ & $\begin{array}{l}11 \text { vs } \\
12+22\end{array}$ & $\begin{array}{l}\text { ARMITAGE'S } \\
\text { TEST -P VALUE }\end{array}$ \\
\hline \multirow[t]{15}{*}{ GRIA1 } & $\begin{array}{l}\text { RS548294 } \\
\text { C/T }\end{array}$ & CONTROLS & 260 & $34 \%$ & & $125(48,1 \%)$ & $102(39,2 \%)$ & $33(12,7 \%)$ & & & & & \\
\hline & & CONT.FEMALE & 204 & $32,3 \%$ & & $98(48 \%)$ & $80(39,2 \%)$ & $26(12,8 \%)$ & & & & & \\
\hline & & CONT. MALE & 56 & $32,1 \%$ & & $27(48,2 \%)$ & $22(39,3 \%)$ & $7(12,5 \%)$ & & & & & \\
\hline & & MIGRAINE ALL & 244 & $44,3 \%$ & $97 \%$ & $80(32,8 \%)$ & $112(45,9 \%)$ & $52(21,3 \%)$ & $\begin{array}{l}\mathbf{0 , 0 0 0 0 9} \\
(\mathbf{0 , 0 0 2 *}) \\
(\mathrm{OR} 1,7 / \mathrm{Cl} \\
1,2-2,1)\end{array}$ & $\begin{array}{l}\mathbf{0 , 0 0 6}\left(\mathrm{NS}^{*}\right) \\
(\mathrm{OR} 1,7 / \mathrm{Cl} 1,1-2,5)\end{array}$ & $\begin{array}{l}\mathbf{0 , 0 0 0 5}(\mathbf{0 , 0 1 *}) \\
(\mathrm{OR} 2,4 / \mathrm{Cl} 1,5-4,1)\end{array}$ & $\begin{array}{l}\mathbf{0 , 0 0 0 5} \\
(\mathbf{0 , 0 1 * )} \\
(\mathrm{OR} 1,9 / \mathrm{Cl} \\
1,3-2,7)\end{array}$ & $0,0002\left(0,005^{*}\right)$ \\
\hline & & MA & 135 & $42,6 \%$ & $80 \%$ & $52(38,5 \%)$ & $51(37,8 \%)$ & $32(23,7 \%)$ & $\begin{array}{l}\mathbf{0 , 0 0 4}\left(\mathrm{NS}^{*}\right) \\
(\mathrm{OR} 1,6 / \mathrm{Cl} \\
1,1-2,1)\end{array}$ & $0,4\left(\mathrm{NS}^{*}\right)$ & $\begin{array}{l}\mathbf{0 , 0 0 4}\left(\mathrm{NS}^{*}\right) \\
(\mathrm{OR} 2,3 / \mathrm{Cl} 1,3-4,1)\end{array}$ & $0,07\left(\mathrm{NS}^{*}\right)$ & $0,007\left(\mathrm{NS}^{*}\right)$ \\
\hline & & MO & 109 & $46,3 \%$ & $78 \%$ & $28(25,7 \%)$ & $61(56 \%)$ & $20(18,3 \%)$ & $\begin{array}{l}\mathbf{0 , 0 0 0 3}(\mathbf{0 , 0 0 8 *}) \\
(\mathrm{OR} 1,8 / \mathrm{Cl} \\
1,3-2,5)\end{array}$ & $\begin{array}{l}\mathbf{0 , 0 0 0 1}(\mathbf{0 , 0 0 3 *}) \\
(\mathrm{OR} 2,6 / \mathrm{Cl} 1 \\
6-4,5)\end{array}$ & $\begin{array}{l}\mathbf{0 , 0 0 3}\left(\mathrm{NS}^{*}\right) \\
(\mathrm{OR} 2,7 / \mathrm{Cl} 1,3-5,3)\end{array}$ & $\begin{array}{l}\mathbf{0 , 0 0 0 0 7} \\
(\mathbf{0 , 0 0 2}) \\
(\mathrm{OR} 2,7 / \mathrm{Cl} \\
1,6-4,3)\end{array}$ & $0,0004\left(0,01^{*}\right)$ \\
\hline & & MIG. FEMALE & 188 & $44,1 \%$ & $90 \%$ & $63(33,5 \%)$ & $84(44,7 \%)$ & $41(21,5 \%)$ & $\begin{array}{l}\mathbf{0 , 0 0 0 7}(\mathbf{0 , 0 2 *}) \\
(\mathrm{OR} 1,6 / \mathrm{Cl} \\
1,2-2,2)\end{array}$ & $\begin{array}{l}\mathbf{0 , 0 2}\left(\mathrm{NS}^{*}\right) \\
(\mathrm{OR} \mathrm{1,6/Cl} \mathrm{1,} \\
0-2,5)\end{array}$ & $\begin{array}{l}\mathbf{0 , 0 0 2}(\mathbf{0 , 0 5 *}) \\
(\mathrm{OR} 2,4 / \mathrm{Cl} 1,3-4,4)\end{array}$ & $\begin{array}{l}\mathbf{0 , 0 0 3} \\
\left(\mathrm{NS}^{*}\right) \\
(\mathrm{OR} 1,8 / \mathrm{Cl} \\
1,2-2,7)\end{array}$ & $0,001(0,03 *)$ \\
\hline & & MIG. MALE & 56 & $41 \%$ & $38 \%$ & $19(34 \%)$ & $28(50 \%)$ & $9(16 \%)$ & 0,1 & 0,1 & 0,3 & 0,1 & 0,1 \\
\hline & $\begin{array}{l}\text { RS2195450 } \\
\text { G/A }\end{array}$ & CONTROLS & 260 & $34,2 \%$ & & $128(49,2 \%)$ & 86 (33\%) & $46(17,8 \%)$ & & & & & \\
\hline & & CONT. FEMALE & 204 & $34,5 \%$ & & $95(46,6 \%)$ & $77(37,7 \%)$ & $32(15,7 \%)$ & & & & & \\
\hline & & CONT. MALE & 56 & $33 \%$ & & $30(53,6 \%)$ & $15(26,7 \%)$ & $11(19,6 \%)$ & & & & & \\
\hline & & MIGRAINE ALL & 244 & $45,5 \%$ & $97 \%$ & $98(40,1 \%)$ & $70(28,7 \%)$ & $76(31,2 \%)$ & $\begin{array}{l}\mathbf{0 , 0 0 0 2}(\mathbf{0 , 0 0 5} \text { *) } \\
(\mathrm{OR} 1,6 / \mathrm{Cl} \\
1,-2,0)\end{array}$ & 0,7 & $\begin{array}{l}\mathbf{0 , 0 0 0 7}(\mathbf{0 , 0 2 *}) \\
(\mathrm{OR} 2,1 / \mathrm{Cl} 1,3-3,3)\end{array}$ & $\begin{array}{l}\mathbf{0 , 0 4}\left(\mathrm{NS}^{*}\right) \\
(\mathrm{OR} 1,4 / \mathrm{Cl} \\
1-2)\end{array}$ & $0,001(0,03 *)$ \\
\hline & & MA & 135 & $50 \%$ & $80 \%$ & $51(38 \%)$ & $33(24 \%)$ & $51(38 \%)$ & $\begin{array}{l}\mathbf{0 , 0 0 0 0 2} \\
(\mathbf{0 , 0 0 0 5 * )} \\
(\mathrm{OR} 1,9 / \mathrm{Cl} \\
1,4-2,5)\end{array}$ & 0,8 & $\begin{array}{l}\mathbf{0 , 0 0 0 0 8}(\mathbf{0 , 0 0 2 *}) \\
(\mathrm{OR} 2,7 / \mathrm{Cl} 1,6-4,6)\end{array}$ & $\begin{array}{l}\mathbf{0 , 0 3}\left(\mathrm{NS}^{*}\right) \\
(\mathrm{OR} 1,6 / \mathrm{Cl} \\
1,0-2,4)\end{array}$ & $0,0002(0,005 *)$ \\
\hline & & MO & 109 & $39 \%$ & $78 \%$ & $47(43,2 \%)$ & $39(35,7 \%)$ & $23(21,1 \%)$ & 0,2 & 0,4 & 0,3 & 0,2 & 0,2 \\
\hline & & MIG. FEMALE & 188 & $42,3 \%$ & $90 \%$ & $83(44,1 \%)$ & $51(27,1 \%)$ & $54(28,8 \%)$ & $\begin{array}{l}\mathbf{0 , 0 2}\left(\mathrm{NS}^{*}\right) \\
(\mathrm{OR} 1,3 / \mathrm{Cl} 1-1,8)\end{array}$ & 0,2 & $\begin{array}{l}\mathbf{0 , 0 1}\left(\mathrm{NS}^{*}\right) \\
(\mathrm{OR} 1,9 / \mathrm{Cl} 1,1-3,2)\end{array}$ & 0,6 & $0,05\left(\mathrm{NS}^{*}\right)$ \\
\hline
\end{tabular}


Table 2: Allele and genotype frequencies of GRIA1 and GRIA3 polymorphisms in Italian patients and controls and association results (Continued)

\begin{tabular}{|c|c|c|c|c|c|c|c|c|c|c|c|c|c|}
\hline & & MIG. MALE & 56 & $53,5 \%$ & $38 \%$ & $17(30,3 \%)$ & $18(32,1 \%)$ & $21(37,5 \%)$ & $\begin{array}{l}\mathbf{0 , 0 0 1}(\mathbf{0 , 0 3 *}) \\
(\mathrm{OR} 2,3 / \mathrm{Cl} 1,3-4)\end{array}$ & 0,1 & $\begin{array}{l}\mathbf{0 , 0 1}\left(\mathrm{NS}^{*}\right) \\
(\mathrm{OR} 3,3 / \mathrm{Cl} 1,3-8,6)\end{array}$ & $\begin{array}{l}\mathbf{0 , 0 1}\left(\mathrm{NS}^{*}\right) \\
(\mathrm{OR} 2,6 / \mathrm{Cl} \\
1,2-5,7)\end{array}$ & $0,008\left(\mathrm{NS}^{*}\right)$ \\
\hline \multirow[t]{7}{*}{ GRIA3 } & $\begin{array}{l}\text { RS3761555 } \\
\text { T/C }\end{array}$ & CONTROLS & 260 & $22,3 \%$ & & $170(65,3 \%)$ & $64(24,6 \%)$ & $26(10,1 \%)$ & & & & & \\
\hline & & CONT.FEMALE & 204 & $23,5 \%$ & & $124(60,7 \%)$ & $64(31,3 \%)$ & $16(8 \%)$ & & & & & \\
\hline & & CONT. MALE & 56 & $17,9 \%$ & & $46(82,1 \%)$ & & $10(17,9 \%)$ & & & & & \\
\hline & & MIG. FEM.ALL & 188 & $34,6 \%$ & $93 \%$ & $83(44,1 \%)$ & $80(42,5 \%)$ & $25(13,4 \%)$ & $\begin{array}{l}\mathbf{0 , 0 0 0 6}(\mathbf{0 , 0 1 * )} \\
\text { (OR } 1,7 / \mathrm{Cl} \\
1,2-2,3)\end{array}$ & $\begin{array}{l}\mathbf{0 , 0 0 4}\left(\mathrm{NS}^{*}\right) \\
(\mathrm{OR} 1,8 / \mathrm{Cl} 1,2-2,8)\end{array}$ & $\begin{array}{l}\mathbf{0 , 0 1}\left(\mathrm{NS}^{*}\right) \\
(\mathrm{OR} 2,3 / \mathrm{Cl} 1,1-4,6)\end{array}$ & $\begin{array}{l}\mathbf{0 , 0 0 0 9} \\
(\mathbf{0 , 0 2 *}) \\
(\mathrm{OR} 1,9 / \mathrm{Cl} \\
1,3-2,9)\end{array}$ & $0,001\left(0,003^{*}\right)$ \\
\hline & & MA-FEMALE & 112 & $38 \%$ & $84 \%$ & $44(39,3 \%)$ & $51(45,5 \%)$ & $17(15,2 \%)$ & $\begin{array}{l}\mathbf{0 , 0 0 0 1}(\mathbf{0 , 0 0 3 * )} \\
\text { (OR } 2 / \mathrm{Cl} \\
1,4-2,8)\end{array}$ & $\begin{array}{l}\mathbf{0 , 0 0 1}\left(0,03^{*}\right) \\
\text { (OR } 2,3 / \mathrm{Cl} 1,3-3,7)\end{array}$ & $\begin{array}{l}\mathbf{0 , 0 0 3}\left(\mathrm{NS}^{*}\right) \\
(\mathrm{OR} 3 / \mathrm{Cl} 1,4-6,4)\end{array}$ & $\begin{array}{l}\mathbf{0 , 0 0 0 2} \\
(\mathbf{0 , 0 0 5 * )} \\
(\mathrm{OR} 2,4 / \mathrm{Cl} \\
1,5-3,8)\end{array}$ & $0,0002(0,005 *)$ \\
\hline & & MO-FEMALE & 76 & $30 \%$ & $73 \%$ & $38(50 \%)$ & $30(39,5 \%)$ & $8(10,5 \%)$ & 0,1 & 0,1 & 0,2 & 0,1 & 0,1 \\
\hline & & MIG. MALE & 56 & & $40 \%$ & $36(64,5 \%)$ & & $20(35,5 \%)$ & $\begin{array}{l}\mathbf{0 , 0 3}\left(\mathrm{NS}^{*}\right) \\
\text { (OR } 2,46 / \mathrm{Cl} \\
1,07-5,6)\end{array}$ & & & & \\
\hline
\end{tabular}


OR of 2.1. Conversely, the putative protective haplotype C_G (rs548294- rs2195450) was more frequent in controls than in cases resulting in a p-value of 0.00001 and an OR of 0.4 (Table 3).

Possible additive interactions of the two most associated SNPs in GRIA1 (rs548294) and GRIA3 (rs3761555) genes were evaluated in those subjects who had both SNPs characterization. GRIA1 SNP rs2195450 was not analyzed because it was in HWD. In Migraine patients, the p-value for the sole risk allele of the GRIA1 gene (TT/ $\mathrm{TT}, \mathrm{CT} / \mathrm{TT}$ genotypes) was 0.03 , OR $1.68(\mathrm{CI}=1.02$ 2.77); the p-value for the sole risk allele of the GRIA3 gene $(\mathrm{CC} / \mathrm{TC}, \mathrm{CC} / \mathrm{CC}$ genotypes) was $0.005,2.28(\mathrm{CI}=$ 1.27-4.11) and the $\mathrm{p}$-value for the combined two risk alleles (TT/TC, TT/CC, CT/TC, CT/CC genotypes) was 0.00001, OR 3.35 (CI = 1.96-5.74) (Table 4).

\section{$-1952 \mathrm{~T}>\mathrm{C}$ variant in GRIA3 regulative region have functional significance}

Bioinformatics predictions by TRANSFAC [16] showed that the $-1952 \mathrm{~T}>\mathrm{C}$ associated variant could affect the putative transcription factor binding sites HSF (Heat Shock Factor) and CdxA. To determine whether the c.1952T >C SNP alters nuclear protein-DNA interactions, EMSAs were performed using radio-labelled oligonucleotide probes containing either $-1952 \mathrm{~T}$ or $-1952 \mathrm{C}$ (see materials and methods). Two distinct complexes were revealed on incubation of the probes with nuclear extract from unstimulated HEK293T cells (figure 2A) and the $1952 \mathrm{~T}$ probe showed stronger DNA protein-binding activity compared with the $-1952 \mathrm{C}$ probe. EMSA assay was also performed using nuclear extract from neuroblastoma cell line SH5Y5Y and obtained the same results (data not shown). To further assess the binding specificity and the differences in binding affinity between the $\mathrm{T}$ and $\mathrm{C}$ allele, competition assay was performed with unlabeled $-1952 \mathrm{~T}$ or $-1952 \mathrm{C}$ oligonucleotide. The results revealed that unlabeled $-1952 \mathrm{~T}$ oligonucleotide but not $-1952 \mathrm{C}$ with 100- fold molar excess fully blocked the binding of the radiolabeled $-1952 \mathrm{~T}$ probe or $-1952 \mathrm{C}$ probe with nuclear protein(s). Moreover, to determine if HSF1 is one of the transcription factors bound to the complexes, antiHSF1 antibody was used in super shift assays. In these experimental conditions none of the complexes was specific for HSF1 (figure 2A). These data suggest that the $1952 \mathrm{~T}>\mathrm{C}$ polymorphism can affect the binding affinity of the GRIA3 promoter with several transcription factor(s) and the variant $\mathrm{T}$ allele has a stronger binding strength compared with the $\mathrm{C}$ allele. To test the functional effect of the $-1952 \mathrm{~T}>\mathrm{C}$ variant we performed the luciferase assay using the promoter region of GRIA3 gene.

When HEK293T cells were transfected with the -1411 to +325 region, the luciferase activity generated by the $\mathrm{C}$ construct was similar to that generated by the $\mathrm{T}$ con- struct but interestingly, under heat shock condition (at $40^{\circ} \mathrm{C}$ for $1 \mathrm{~h}$ ) the luciferase activity generated by the $\mathrm{C}$ construct was 1.3 -fold greater than that generated by the $\mathrm{T}$ construct (figure 3 ).

\section{Functional analysis of the associated GRIA1 variants}

Bioinformatics predictions did not show any clear alteration of transcription factor binding sites both for SNP $2012 \mathrm{C}>\mathrm{T}$ and $+561 \mathrm{G}>\mathrm{A}$. To determine whether these variations could alter nuclear protein-DNA interactions we performed EMSAs assays using radiolabelled oligonucleotide probes containing either $-2012 \mathrm{C}$ or $-2012 \mathrm{~T}$ and $+561 \mathrm{G}$ or $+561 \mathrm{~A}$ (see materials and methods) (figure 2B). No binding affinity was revealed for both $+561 \mathrm{G}$ and $+561 \mathrm{~A}$ alleles. In contrast, two distinct complexes were revealed on incubation of the probes $-2012 \mathrm{~T}$ and $-2012 \mathrm{C}$ with nuclear extract from unstimulated HEK293T cells and in particular, the $-2012 \mathrm{~T}$ probe showed stronger DNA protein-binding activity compared with the $-2012 \mathrm{C}$ probe (figure $2 \mathrm{~B}$ ). The binding specificity and the differences in binding affinity between the $\mathrm{T}$ and $\mathrm{C}$ allele was also demonstrated in competition assay using unlabeled $2012 \mathrm{~T}$ or $-2012 \mathrm{C}$ oligonucleotide. The results revealed that unlabeled $-2012 \mathrm{~T}$ oligonucleotide but not $-2012 \mathrm{C}$ with 100- fold molar excess fully blocked the binding of the radiolabeled $-2012 \mathrm{~T}$ probe or $-2012 \mathrm{C}$ probe with nuclear protein(s) (figure 2B).

\section{GRIAs comparative analysis}

The identification of associated variants in the promoter regions of both GRIA1 and GRIA3 genes and their evidence for functional roles, suggested us to investigate about the evolutive conservation of this class of genes. We selected from databases the full-length sequences of the transcripts of GRIA1-GRIA4 genes and the regulative regions at the $5^{\prime}$ of each gene. To postulate a coordinate regulation of these genes, all sequences were compared using the vista software and the results suggest that GRIA1 seems be the ancestral gene and is more similar to GRIA3 gene as for other genes (GRIA2 and GRIA4) (figure 4).

\section{Discussion}

Glutamate is a major excitatory neurotransmitter in the central nervous system, thought to be widely involved in migraine mechanisms. Indeed, migraine brain nociceptive centres, including the trigeminal ganglion, trigeminal nucleus caudalis, and thalamus, contain glutamate-positive neurons, and glutamate activates the trigeminal nucleus caudalis. Glutamate is implicated in cortical spreading depression (CSD), trigemino-vascular activation, and central sensitization [17]. These observations argue for a strong link between migraine and the glutamatergic system. A link that is important to further char- 
Table 3: Frequency of common GRIA1 haplotypes in migraine patients compared with healthy controls.

\begin{tabular}{lccccccc}
\hline HAPLOTYPE & CASES N= 452 & PERCENTAGE & $\begin{array}{l}\text { CONTROLS } \\
\mathbf{N = 5 0 4}\end{array}$ & PERCENTAGE & P-VALUE & $\begin{array}{l}\text { ODDS } \\
\text { RATIO }\end{array}$ & $\begin{array}{l}\text { 95\% } \\
\text { CONFIDENCE } \\
\text { INTERVAL }\end{array}$ \\
\hline C_A & 149 & $33 \%$ & 131 & $26 \%$ & 0.0180 & 1.40 & $1.06-1.85$ \\
C_G & 99 & $22 \%$ & 207 & $41 \%$ & 0.00001 & 0.40 & $0.30-0.54$ \\
T_A & 59 & $13 \%$ & 35 & $7 \%$ & 0.0015 & 2.10 & $1.30-3.12$ \\
T_G & 145 & $32 \%$ & 131 & $26 \%$ & 0.0381 & 1.34 & $1.02-1.78$ \\
\hline
\end{tabular}

acterization and understanding of migraine mechanisms in order to deliver effective therapies.

In this study we have investigated the role of glutamate receptors, ionotropic, AMPA (GRIA1, GRIA2 GRIA3 and GRIA4 genes) and their variants in MA and MO. We found two variants in GRIA1 gene (rs548294 and rs2195450) and one variant in GRIA3 gene (rs3761555), all located in the regulative region of the genes, to be associated with the migraine phenotype in an Italian population. Interestingly, both the GRIA1 and GRIA3 variants were specifically associated with MA suggesting a role of these genes in CSD, which is retained to be the path physiological mechanism-underlying aura. However, to date we cannot exclude that these variant can also be associated to MO phenotype due to limited size of MO subgroup. In fact, the rs548294 SNP in GRIA1 gene was primarily associated with $\mathrm{MO}$ rather than MA. Although MO and MA are separate categories according to the ICHD-II criteria these two subtypes of migraine share some path physiological mechanisms [18]. Several studies support that the same SNP or different SNPs in the same gene could be associated with both $\mathrm{MO}$ and MA phenotypes [5].

We analyzed the distribution of the haplotypes formed by the associated SNPs in GRIA1 gene in cases and controls. Haplotype-specific testing showed that the putative risk haplotype $\mathrm{T}_{-} \mathrm{A}$ was more frequent in cases than in controls $(13 \%$ and $7 \%$, respectively, $\mathrm{P}=0.001)$ and was associated with increased risk of migraine $(\mathrm{OR}=2,10$; $95 \%$ CI $(1.30-3,12))$ compared with the risk of the two alleles taken separately. Furthermore, our analysis of the combined effects of the two SNPs in GRIA1 (rs548294) and GRIA3 (rs3761555) genes not supported a synergy of the two SNPs in the genetic susceptibility to migraine. Indeed, in migraine patients, the combined two risk allele genotypes exhibited an OR that was more or less the sum of the ORs of each risk allele taken separately, suggesting that, when both risk alleles are present, the risk to develop migraine is merely the sum of the effect carried by each single risk allele.

Although our data need to be confirmed in more numerous series as well as in populations of different origin, the identification of a statistically significant genetic link between glutamate receptor genes and MA needs to be highlighted. A growing number of scientific report based on preclinical and clinical data argue strongly for a role of glutamatergic receptor activation in migraine and in particular in CSD [19]. Despite the remarkable advancing in the pharmacotherapy, there is still a tremendous need for the research of more effective treatments. Glutamate receptors antagonists have been recently proposed as major target addressed for the treatment of migraine. Glutamate receptors indeed represent a promising target for a valuable, non-vasoactive oriented approach to the treatment of migraine [20].

The SNP rs2195450, which shows the strongest association, is in Hardy-Weinberg disequilibrium (DHW) both in controls and in patients. DHW may be due to several factors including genotyping errors, inappropriate population stratification and selection, inbreeding, presence of

Table 4: Combined genotypic frequencies of GRIA1 (CT) and GRIA3 (TC)

\begin{tabular}{|c|c|c|c|c|c|}
\hline & CONTROLS N = 260 & CASES N = 244 & P-VALUE & OR & $95 \% \mathrm{Cl}$ \\
\hline TWO RISK ALLELES & $6+3+31+9(19 \%)$ & $24+6+29+22(33 \%)$ & 0.00001 & 3.35 & $1.96-5.74$ \\
\hline ONE RISK ALLELE (GRIA1) & $26+74(39 \%)$ & $20+63(34 \%)$ & 0.03 & 1.68 & $1.02-2.77$ \\
\hline ONE RISK ALLELE (GRIA3) & $26+14(15 \%)$ & $27+18(19 \%)$ & 0.005 & 2.28 & $1.27-4.11$ \\
\hline NO RISK ALLELE & $71(27 \%)$ & $35(14 \%)$ & & & \\
\hline
\end{tabular}

Genotypes for two risk alleles were: TT/TC + TT/CC + CT/TC + CT/CC; one risk allele (GRIA1): TT/TT + CT/TT; one risk allele (GRIA3): CC/TC + CC/ CC; no risk allele: CC/TT. 


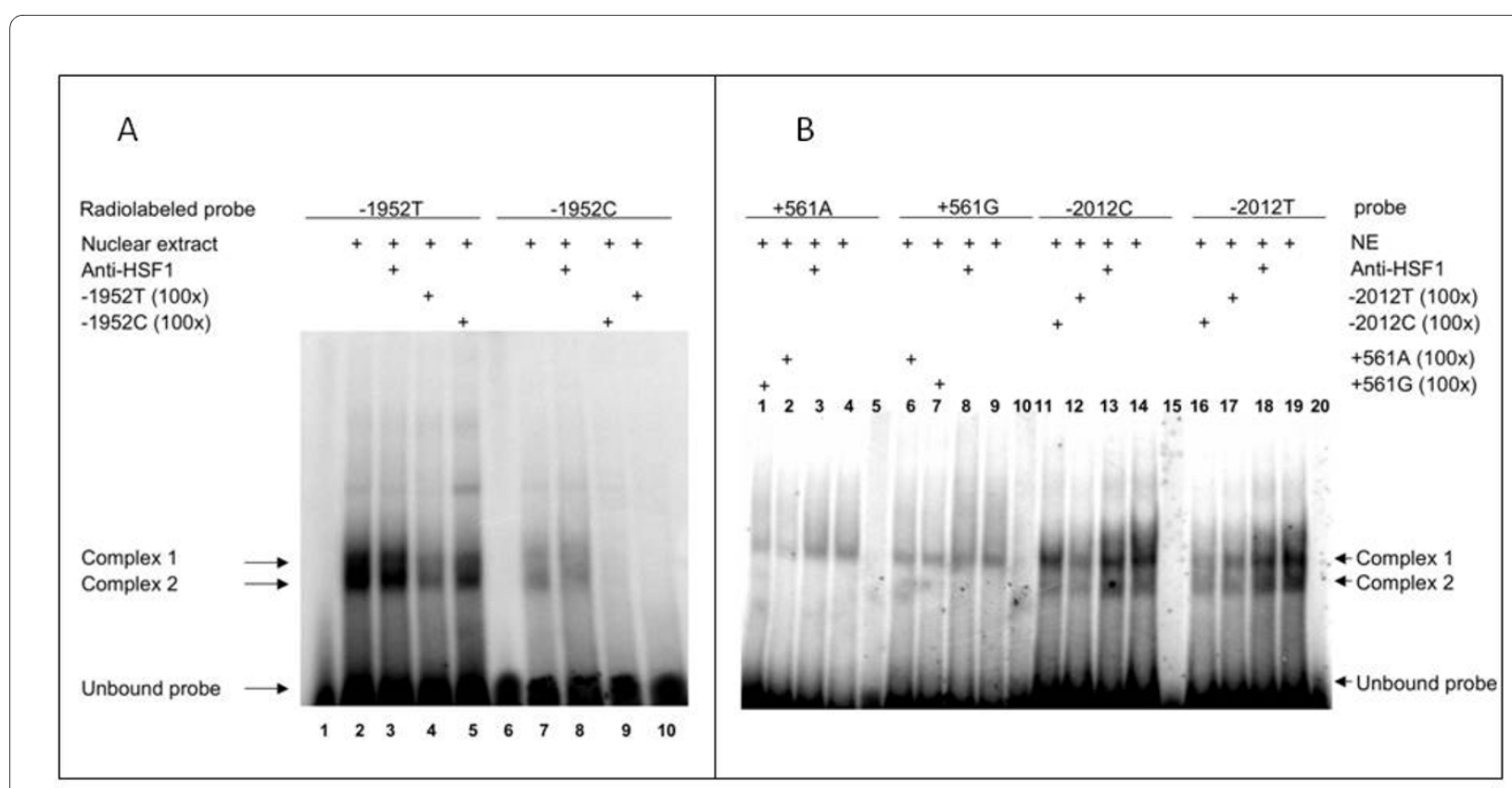

Figure $2 \mathrm{~A}$, electrophoretic mobility shift assay (EMSA) with radiolabeled either $-1952 \mathrm{~T}$ or $-1952 \mathrm{C}$ probe and HEK-293 cell nuclear extracts (NE) and B, EMSA assays with radiolabeled either $-2012 \mathrm{~T} /-2012 \mathrm{C}$ and $+561 \mathrm{G} /+561 \mathrm{~A}$ probes and HEK-293 cell NE. A. Lanes 1 and 6 , mobility of the labelled probes without NE; lanes 2 and 7, mobility of the labelled probes with NE in the absence of competitor. A specific nuclear protein binding can be almost completely abolished both by 100-fold unlabeled -1952T but not with -1952C probe (lanes 4 and 5; lanes 9 and 10). Super shift assays incubating with anti-HSF1 antibody did not show any super shifted protein complex (lanes 3 and 8). B. Lanes 5, 10, 15 and 20, mobility of the labelled probes without NE; lanes 4, 9, 14, and 19, mobility of the labelled probes with NE in the absence of competitor. Competition assays with 100fold unlabeled probes (lanes 1 and 2; lanes 6 and 7; lanes 11 and 12; lanes 16 and 17). Super shift assays incubating with anti-HSF1 antibody did not show any super shifted protein complex (lanes 3,8,13 and 18).

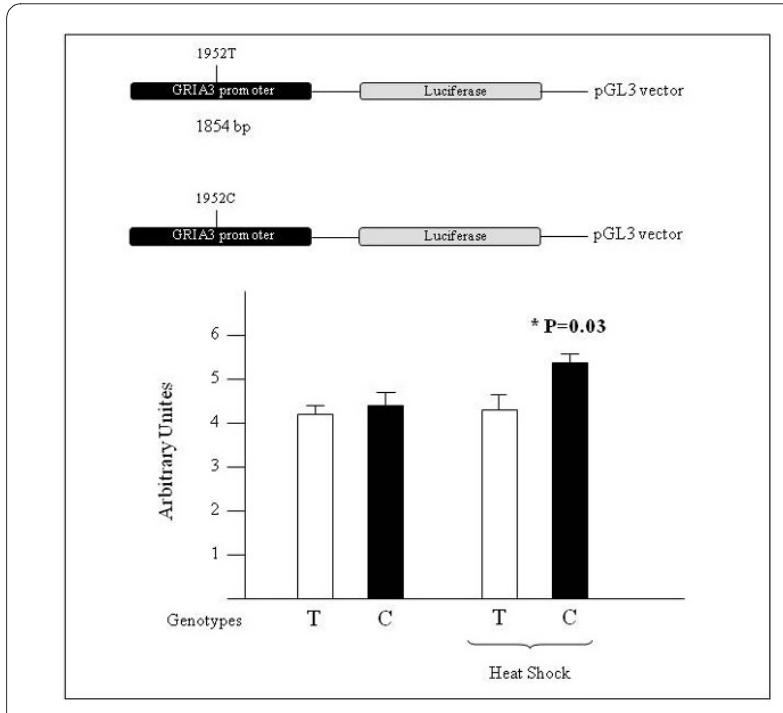

Figure 3 Luciferase assay for GRIA3 promoter activity. Under heat shock condition the luciferase activity generated by the $C$ construct was 1.3-fold greater than that generated by the T construct $(p<0.05$ using t-test calculation). a causative allele or simply the chance. We can exclude with high confidence that DHW as well as patient-control differences could be due to genotyping errors. For all SNPs, about 20 subjects were randomly selected and sequenced; for rs 2195450 the sample was increased to 100 subjects. The original classification was confirmed in all samples. Moreover, for the autosome genes, the presence of DHW in different direction in controls and in patients, as observed for rs2195450, is compatible with the segregation of a causative variant according to a dominant model [21]. However, we cannot exclude that DHW is due to other confounding factors, and then the association of this SNP must be considered with prudence. Further remarkable in our cohort is that GRIA1 and GRIA3 variants are associated to migraine in female but not in male subjects. To date we cannot assert that AMPA receptor genes and genetic variations within them may act differently in the two sexes, in light of the small sample size of case males that do not provide enough statistical power to detect association.

However, the underlying mechanism by which these variants confer susceptibility to migraine remains unclear. Bioinformatics predictions showed that the $\mathrm{C}$ 


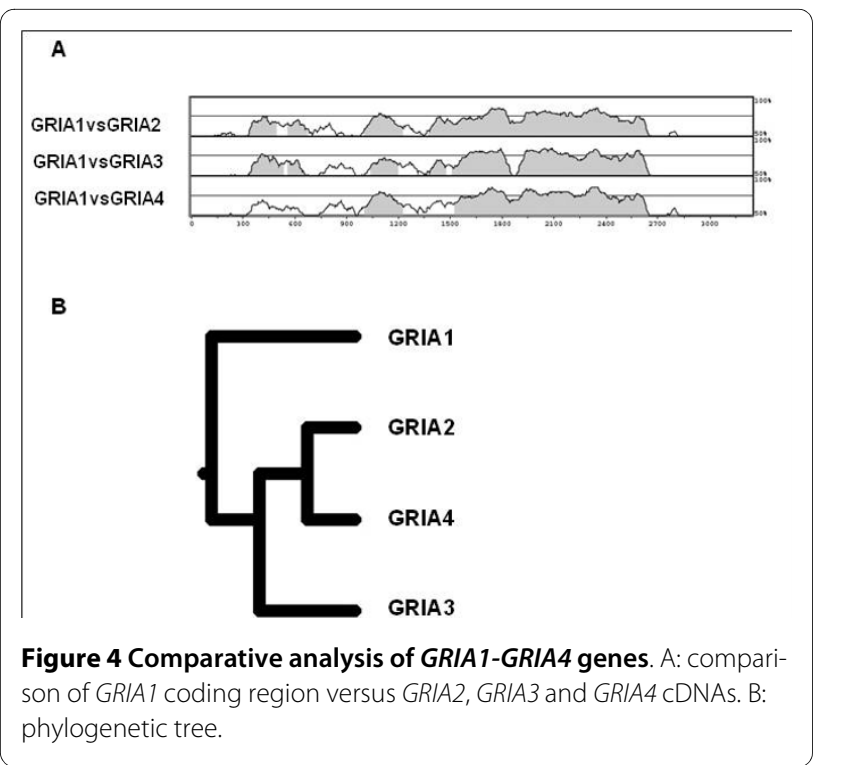

variant of GRIA3 gene could affect putative binding sites for transcription factors altering the consensus sequence. We strengthened this hypothesis by transfecting the HEK293T cells with a promoter region of GRIA3 gene. It should be highlighted that, under stress condition the luciferase activity generated by the $\mathrm{C}$ construct (associated allele) was 1.3-fold greater than that generated by the $\mathrm{T}$ construct. Moreover, EMSA assays suggest that the $1952 \mathrm{~T}>\mathrm{C}$ polymorphism can affect the binding affinity of the GRIA3 promoter with transcription factor(s) and the variant $\mathrm{T}$ allele has a stronger binding strength compared with the $\mathrm{C}$ allele. Considering that the $\mathrm{T}$-allele displays lower promoter transcription activity, we infer that the nuclear factor(s) bound to the region covering the $1952 \mathrm{~T}>\mathrm{C}$ polymorphism may function as negative regulator(s) for GRIA3 transcription. Therefore, the $1952 \mathrm{~T}>\mathrm{C}$ polymorphism may affect the GRIA3 promoter binding affinity with nuclear proteins and in turn the GRIA3 expression, which consequently modulates the individual's susceptibility to migraine. Future genetic and functional studies are necessary to further elucidate the role of GRIA3 in migraine susceptibility. Preliminary results using an Australian case-control panel indicate that the same $-1952 \mathrm{~T}>\mathrm{C}$ polymorphism showed a trend of association with migraine $(\mathrm{p}=0.04)$ (L. Griffiths personal communication).

More complex is the case of GRIA1 gene where only the $-2012 C>T$ variant seems to affect the binding affinity of the GRIA1 promoter with transcription factor(s) and the variant $\mathrm{T}$ allele has a stronger binding strength compared with the $\mathrm{C}$ allele. Considering that the $\mathrm{T}$-allele is also the risk allele we can infer that nuclear factor/s bound to the region covering the $-2012 \mathrm{C}>\mathrm{T}$ polymorphism may function as positive regulator(s) for GRIA1 transcription.

\section{Conclusions}

These results indicate an involvement of GRIA1 and GRIA3 genes in the susceptibility to migraine with aura and encourage replication in other data sets. Moreover, functional investigations to explain the role of glutamate receptors variants in MA might be useful.

\section{Competing interests}

The authors declare that they have no competing interests.

\section{Authors' contributions}

DF, AA, FG and TE were responsible for undertaking all the experiments and the analysis of data. SS, OF DD and GDI were responsible for patients and controls collection. LRG revised the manuscript. All authors read and approved the final manuscript.

\section{Acknowledgements}

Migraine Research Foundation to T. Esposito supported this research. The Short-term Mobility Program from the Italian National Research Council also supported F. Gianfrancesco and T. Esposito. The authors would like to express their most sincere gratitude to Dr. R.T. Ngomba for critical reading of the manuscript, Dr. Serena Mirra for support in luciferase assay and Dr. Maria Mancini for support in EMSA assay.

\section{Author Details}

IInstitute of Genetics and Biophysics, Italian National Research Council, Naples, Italy, ${ }^{2 H e a d a c h e ~ S e r v i c e ~-~ D e p a r t m e n t ~ o f ~ N e u r o l o g i c a l ~ S c i e n c e s, ~ S e c o n d ~}$ University of Naples, Naples, Italy and ${ }^{3}$ Genomics Research Centre, School of Medical Science, Griffith University, Gold Coast, Queensland, Australia

Received: 21 January 2010 Accepted: 25 June 2010

Published: 25 June 2010

\section{References}

1. Kors EE, van den Maagdenberg AM, Plomp JJ, Frants RR, Ferrari MD: Calcium channel mutations and migraine. Curr Opin Neurol 2002, 15(3):311-316.

2. De Fusco M, Marconi R, Silvestri L, et al:: Haploinsufficiency of ATP1A2 encoding the $\mathrm{Na}+/ \mathrm{K}+$ pump alpha2 subunit associated with familial hemiplegic migraine type 2. Nat Genet 2003, 33(2):192-196.

3. Dichgans $M$, Freilinger T, Eckstein $G$, et al:: Mutation in the neuronal voltage-gated sodium channel SCN1A in familial hemiplegic migraine. Lancet 2005, 366(9483):371-374

4. de Vries B, Frants RR, Ferrari MD, van den Maagdenberg AMJM: Molecular genetics of migraine. Hum Genet 2009. DOI 10.1007/s00439-009-0684-Z

5. Colson NJ, Fernandez F, Lea RA, Griffiths LR: The search for migraine genes: an overview of current knowledge. Cell Mol Life Sci 2007, 64:331-344

6. Bergerot A, Holland PR, Akerman S, et al:: Animal models of migraine: looking at the component parts of a complex disorder. Eur J Neurosci 2006, 24(6):1517-34

7. Tottene A, Conti R, Fabbro A, et al.: Enhanced excitatory transmission at cortical synapses as the basis for facilitated spreading depression in Ca(v)2.1 knockin migraine mice. Neuron 2009, 61:762-773.

8. Ramadan NM: The link between glutamate and migraine. CNS Spectr 2003, 8:446-449.

9. Miller SA, Dykes DD, Polesky HF: A simple salting out procedure for extracting DNA from human nucleated cells. Nucleic Acids Res 1988, 16:1215.

10. Headache Classification Committee of the International Headache Society: The International Classification of Headache Disorders, 2nd Edition. Cephalalgia 2004, 24(Supplement 1):1-52.

11. Gabriel SB, Schaffner SF, Nguyen H, et al:: The structure of haplotype blocks in the human genome. Science 2002, 296(5576):2225-9.

12. Nyholt DR, Curtain RP, Griffiths LR: Familial typical migraine: significant linkage and localization of a gene to Xq24-28. Hum Genet 2000, 107:18-23. 
13. Fernandez F, Esposito T, Lea RA, Colson NJ, Ciccodicola A, Gianfrancesco F, Griffiths LR: Investigation of GABA A Receptors Genes and Migraine Susceptibility. BMC Medical Genetics 2008, 16:9-109.

14. Purcell S, Cherny SS, Sham PC: Genetic Power Calculator: design of linkage and association genetic mapping studies of complex traits. Bioinformatics 2003, 19:149-150.

15. Granelli-Piperno A, Nolan P, Inaba K, Steinman RM: The effect of immunosuppressive agents on the induction of nuclear factors that bind to sites on the interleukin 2 promoter. JExp Med 1990, 172:1869-1872.

16. Heinemeyer T, Wingender $E$, Reuter I, et al: Databases on transcriptional regulation: TRANSFAC, TRRD and COMPEL. Nucleic Acids Res 1998, 26:362-367.

17. Vikelis M, Mitsikostas DD: The role of glutamate and its receptors in migraine. CNS Neurol Disord Drug Targets 2007, 6:251-7.

18. Nyholt DR, Gillespie NG, Heath AC, Merikangas KR, Duffy DL, Martin NG: Latent class and genetic analysis does not support migraine with aura and migraine without aura as separate entities. Genet Epidemiol 2004, 26:231-244

19. Dehbandi S, Speckmann EJ, Pape HC, Gorji A: Cortical spreading depression modulates synaptic transmission of the rat lateral amygdala. Eur J Neurosci 2008, 27(8):2057-65.

20. Andreou AP, Goadsby PJ: Therapeutic potential of novel glutamate receptor antagonists in migraine. Expert Opin Investig Drugs 2009 in press.

21. Wittke-Thompson JK, Pluzhnikov A, Cox NJ: Rational inferences about departures from Hardy-Weinberg equilibrium. Am J Hum Genet 2005, 76:967-986.

\section{Pre-publication history}

The pre-publication history for this paper can be accessed here: http://www.biomedcentral.com/1471-2350/11/103/prepub

\section{doi: $10.1186 / 1471-2350-11-103$}

Cite this article as: Formicola et al., Common variants in the regulative regions of GRIA1 and GRIA3 receptor genes are associated with migraine susceptibility BMC Medical Genetics 2010, 11:103

Submit your next manuscript to BioMed Central and take full advantage of:

- Convenient online submission

- Thorough peer review

- No space constraints or color figure charges

- Immediate publication on acceptance

- Inclusion in PubMed, CAS, Scopus and Google Scholar

- Research which is freely available for redistribution

Submit your manuscript at www.biomedcentral.com/submit
C Biomed Central 